\title{
The learning design studio: collaborative design inquiry as teachers' professional development
}

\author{
Yishay Mor $^{a *}$ and Orit Mogilevsky \\ ${ }^{a}$ Institute of Educational Technology, The Open University, Milton Keynes, UK, ${ }^{b}$ Technologies in \\ Education Program, The University of Haifa, Haifa, Israel
}

\begin{abstract}
The learning design studio is a collaborative, blended, project-based framework for training teachers in effective and evidence-based use of educational technology. Arguably, teachers are the primary change agents in any educational system. Several decades of research have produced an extensive body of scientific knowledge of effective ways to use technology to support learning. Yet, if we want to mainstream this knowledge and use it to improve educational systems, we need to make this knowledge available to educational practitioners. The dominant model of teacher education assumes that teachers should be provided with a solid theoretical curriculum, which they will then apply in their practice. This article argues for an alternative - the design-inquiry model and presents the learning design studio as a manifestation of this model.
\end{abstract}

Keywords: learning design; teacher training; learning design studio; design inquiry; inquiry learning

\section{Introduction}

This article presents the Learning Design Studio (LDS), a course format aimed at enculturation of educational professionals into design inquiry of learning.

Arguably, teachers are the primary change agents in any educational system. Teachers operate in a complex and dynamic domain - the background knowledge and practices of their students constantly change, the technologies and resources at their disposal are perpetually evolving, and the guidance and directives they receive are frequently updated. Within this domain, they need to habitually devise new means for achieving educational goals - engendering change in their students' knowledge, behaviours or attitudes. This calls for a repositioning of educational professionals: from conveyors of knowledge to designers of learning (Mor et al. 2012). Here, we refer to learning design as "the act of devising new practices, plans of activity, resources and tools aimed at achieving particular educational aims in a given situation" (Mor and Craft 2012). In order to be effective learning designers, educational professionals need to assume a creative, proactive, innovative stance towards their practice - but also to base their work on solid scientific foundations. John Hattie lists 116 meta-analyses exploring the use of technology in education, covering 6545 studies and over 4 million subjects (Hattie 2009). However, if we want to mainstream this knowledge and use it to improve educational systems, we need to

*Corresponding author. Email: Yishay.Mor@open.ac.uk 
break out of the academic sphere and make this knowledge available, accessible and relevant to educational practitioners.

The question which follows is: how do we train educators as effective learning designers? How do we empower them to make informed innovations in their daily practice, systematically analysing the context in which they operate, articulating educational challenges, considering the relevant scientific and practical knowledge, and introducing innovations to effectively address the challenges they choose to confront?

This article argues for Design Inquiry of Learning (DIL) as an appropriate pedagogical approach for addressing this question and presents the LDS as an effective manifestation of this approach. We evaluate the LDS format by reviewing two courses that implemented it and discuss its merits and limitations.

\section{Background}

Teacher education is dominated by the "technical-rationality" model (Korthagen et al. 2001). This model assumes that educational theory is fundamental to good teaching practice, and therefore teachers should be provided with a solid theoretical curriculum, which they will then apply in their practice. Korthagen et al. show that this approach fails consistently. Not only do teachers find themselves ill-equipped to translate the theoretical abstractions to the concrete context in which they work, their negative experience in attempting to do so results in feeling threatened by educational theory and seeing teacher education as detached and useless.

In recent years, an alternative view has emerged, positioning teachers as learning designers and focusing on the practical process of devising effective learning experiences (Beetham and Sharpe 2013). Recent studies demonstrate how training teachers as learning designers enhances not only their practical skills but also their theoretical understanding (Cross et al. 2008; Fuhrmann, Kali, and Hoadley 2008; Laurillard 2008; Voogt et al. 2011). One approach which appears to hold significant promise in training learning designers is the LDS (Cox, Harrison, and Hoadley 2008; Hoadley and Cox 2009; Kali and Ronen-Fuhrmann 2011). This approach is modelled after the tradition of studio-instruction in arts and design disciplines (such as architecture). In this model, the main activity of a course is the students' continued work on design challenges in a defined domain of practice. Students typically work in groups. They identify an educational challenge, research it and devise innovative means of addressing it. The course instructor guides the students through the process, and classroom sessions are mostly dedicated to group work and public review of design artefacts.

Laurillard (2012) argues that teaching should be repositioned as a design science, in line with Simon's (1996) paradigmatic distinction between natural science, which describes how the world is, and design science which is concerned with how it should be. Design, in this context, is the informed creative practice of devising "courses of action aimed at changing existing situations into desired ones" (Simon 1996, p. 129). Ideally, we would want teachers to adopt a design science stance towards their practice: "Ideally, teachers should be able to enact design science as part of their normal professional practice" (Laurillard 2012, p. 7). Yet, practitioners do not have the skills or the resources required to conduct a full-scale, scientific study. Instead, we propose a model of DIL - a projection of the ideal of design science into realistic 
settings. DIL combines an inquiry-based learning approach with a design-based scientific paradigm.

Inquiry-based learning attempts to shape educational experiences in the model of scientific investigation. Similarly, a design-inquiry approach to the training of educational practitioners should mimic the form of design research in education.

Design-based research progresses through cycles of theoretical analysis, conjectures, design, implementation, analysis and evaluation - which feed into adjusting the theory and deriving practical artefacts (Mor 2010). Anastopoulou et al. (2012) describe personal inquiry learning as a cycle of questioning, investigation, evidence collection, analysis, sharing and reflection. Applying the pedagogy of inquiry-based learning to the scientific paradigm of design-based research yields the cycle of DIL (Figure 1): imagining a desired change, investigating the current situation, drawing inspiration from theoretical frameworks and exemplars of practice, ideating and designing an innovation, prototyping it, evaluating its effects and reflecting on the process.

Kolodner et al. (2003) present Learning by Design (LBD) as a project-based inquiry approach to middle-school science learning. The DIL approach applies similar principles in the domain of adults learning, a design science of education.

\section{The LDS format}

The LDS adopts the studio-based instructional format (Green and Bonollo 2003) to provide an implementation of the DIL approach in university settings. In the LDS, students work in groups on projects of their own choice. Each group identifies a concrete educational context and a specific educational challenge within this context, locates and reviews relevant literature, devises a techno-pedagogical innovation to address the chosen challenge in its context and evaluates their innovation - if

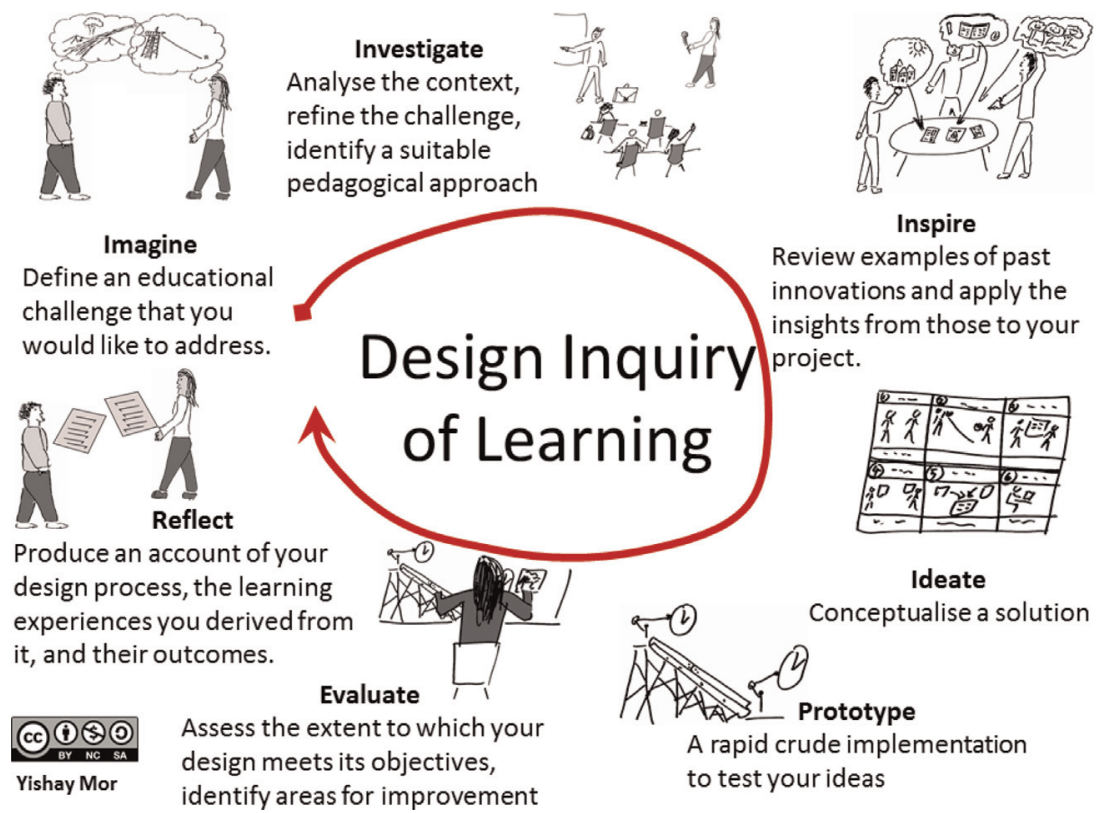

Figure 1. The design inquiry of learning cycle. 
possible, by observing its implementation in the real-world context. The LDS mimics the structure of a design experiment (Mor and Winters 2007), with the exception that students do not have the resources or the time to conduct several iterations, scaling up from a conceptual prototype to an extensive deployment.

The first phase of the LDS focuses on defining the context in which projects will be situated and the pedagogical challenge they attempt to address within this context. Students were asked to propose an idea for a project they would like to develop. They form groups based on common interests and spend the majority of the course time working on their joint project. Students document and describe the material, social and intentional factors which define the environment in which they will work, and represent the relations between these factors in a suitable form, such as a force map (Mor 2011). Reflecting on the tensions identified in the analysis of the context, students specify well-defined and measurable educational objectives. Next, they conduct preliminary research, reviewing appropriate learning theories and relevant case studies, and choosing the theories which they identify with and the cases which inspire them, as a basis for their design work.

Based on their articulation of the context and challenge, and the outcomes of their preliminary research, students develop an initial scenario: an outline of the proposed solution and a storyboard depicting the learner's envisioned activities and expected learning trajectory. In the process, students consult the design principles database (Kali 2006) or appropriate collections of design patterns (Mor and Winters 2007). Students develop prototypes (or paper prototypes) of their solution and preferably act out the activities. After incorporating the lessons learnt from this experience, they proceed to conduct a pilot study in the actual project settings and evaluate the effectiveness of their design. If conducting a pilot study is not possible, students conduct a heuristic evaluation of their design.

The LDS is scaffolded by a website which students use as a collaborative workspace. Students also maintain a learning journal throughout the LDS and comment on their peers work. When the project is completed, students edit their website to present their work - the design process, its outputs and their reflections. At this phase, students review the record of their work and produce a design narrative, recounting their experience and the lessons they learned.

\section{Research context and methodology}

The LDS format was trialled in two courses at the Technologies in Education postgraduate programme at the University of Haifa during the academic year 20102011. This programme, situated in the faculty of education, offers masters and doctoral studies for educational professionals. The first was a course on "games and learning" and the second a course on "mobile learning" (Mor and Mogilevsky 2012). The first course ran for 13 weeks, and included 22 students, who split into 9 project groups. The second course ran for 13 weeks and included 17 students in 6 project groups. Each group maintained a website for their project, instantiated from a template designed to scaffold their design process. The website template contained sections corresponding to the phases of a single iteration of a design experiment. Students replaced the instructions in the template with the content and artefacts they generated in the course of their work, so that when they completed the project, the website presented both its products and the process by which they were created. 
The course websites (in Hebrew) are available as open educational resources at: courses.edtech.haifa.ac.il/games and courses.edtech.haifa.ac.il/mlearning

\section{Research questions}

The first question that needs to be considered is the pedagogical effectiveness of the LDS: does it indeed enculturate students into a practice of DIL and learning design? Does it enhance their theoretical perspective, as well as their practical skills?

The innovative nature of the LDS also raises questions regarding the students' experiences: what were the challenges and dilemmas of students induced by the DIL methodology, and how did the students deal with those challenges? To illuminate this question, we analysed at the end of the course the students' project websites, their design narratives and their learning journals.

\section{Methods}

We examined these questions using a mixed method approach. To assess the pedagogical effectiveness of the LDS, we analysed the students' work at the end of the two courses. This gave us an indication of the LDS's immediate effect. We also surveyed students 2 years after the course ended to assess the LDS's long-term effect.

To understand the learner's experience, we used an autoethnographic research method (one of the authors of this article participated as a student in the course). The main data of this study are the course participants' narratives. Therefore, a narrative research approach was adopted. Narrative research, according to the definition by Josselson and Lieblich (2001), refers to "... any study based on discourse or on people's verbal accounts of their experiences. Such story need not compose a complete autobiography; it may be short descriptive statements or narratives, formed in the teller's personal language and style .... Narrative data include both oral and written accounts. The common aspect of all these narratives is that the material is offered in the natural language of the teller and is created through his or her individual experience and judgment."

At the beginning of the analysis process, the data were mapped and organised by numbers. We counted the numbers of students, projects, narratives, and so on. Our main data were the narratives that the students wrote: the design narratives have been written by the project groups, and the learning journals have been written individually.

The content of the students' narratives was encoded based on the criteria of research question: identifying words expressing difficulties, challenges or dilemmas, descriptions relating to the manner of dealing with these dilemmas as well as reports on solutions and successes.

At the first step of the analysis, the verbal data were categorised into units according to the stages of the design process. We followed each stage and had a review of the texts accordingly, highlighting words relating each one of the stages (without carrying about the meaning of the words). The second step was to focus on each of the stages (for two rotations) and identify the relevant words and their meanings respectively to the research questions (Tables 1 and 2).

Each step in the learning process in the course was addressed by the students, whether positive or negative. This gave us an indication to assess the effectiveness of 


\section{Design and development}

As the first step of the design process, students were requested to define the learning context. To do this, they interviewed a biology teacher at one of the group member's school and constructed a model of the learning and teaching practices related to biotope studies; how do the pupils conduct their inquiries, in the field, at home and in class? How much is the teacher involved in her pupils' learning process and their fieldwork?

The group analysed these practices to identify any gaps and tensions which might impede the pupils' learning. Some of these concerned access to information during fieldwork and a common environment for sharing the collected data. These issues were defined as the design challenge which the project will address. To inform their design, the group reviewed several case studies and possible technologies.

Drawing on the analysis of the context and challenge, and the review of case studies and technologies, the group outlined a solution, which was designed to reinforce the connectivity among the classroom space, the pupils' fieldwork and the teacher. The group proposed a combination of web and mobile technologies to address these needs (Figure 2).

\section{Evaluation}

The next phase was an intensive and iterative process of prototyping, role-playing, experimenting, reviewing and refining the proposed solution. This resulted in a guiding website that combines mobile technologies. This website also provides a portable reference tool, with content, work instructions and tools for collecting data and field notes.

This site was presented to the teacher and her pupils for evaluation. The evaluation group consisted of nine biology pupils, aged 17, and divided into three groups. The pupils were highly proficient mobile users, owning a variety of devices

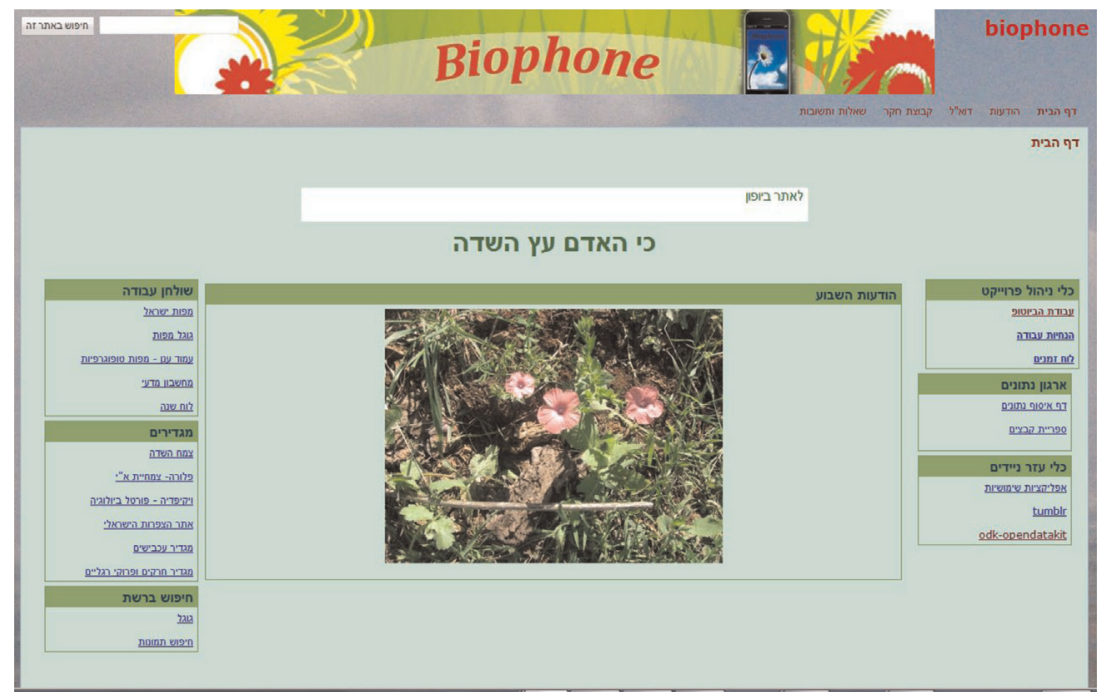

Figure 2. Biophone website. The boxes include: project management tools, data handling, mobile aids, workbench, reference books and search the web. 
(iPad, Android phones and iPhones). They were enthusiastic about participating in the study, and particularly motivated to use their mobile phones in the course of their field studies.

Pupils used the website frequently in the course of their work. They reported that the interface is user friendly and contains necessary details and can be used independently. In addition, using the links from the website for obtaining information was crucial for them in the field and in real time. The pupils entered observation data via online forms and received the data in an organised and clear fashion, for analysis and processing as part of their follow-up desk research.

The biology teacher was very satisfied with the use of the Biophone website to support the Biotope study. She acknowledged the contribution of the organised data and the collected information to the learning process. In addition, she saw an advantage to the feedback that she can offer as a result of the visibility of the regularly processed data.

\section{Reflection}

Reflection on the process as a whole, one student noted: "It took a long way to accomplish the goal. It wasn't easy to design such a learning space. It was big effort for us to transfer the general ideas we had in mind into real ones. We feel that we got useful and practical tools during the 'mobile learning' course for doing the design process. Our experience with collaborative project such as 'Biophone' helped us understand what mobile learning is."

\section{Student's experiences: mobile learning course}

The data suggest that students initially found the design-inquiry approach confusing and engaged with it at a superficial level:

Looking back at our work method, and our way of thinking, it was reverse. Instead of specifying a problem or challenge, then look for a solution to the problem if this application or any other software, we specifically chose the application and tried to put on the program, this method had delayed our progress.

However, these expressions also indicate that in retrospect, students acknowledged the advantages of the design-inquiry approach. To an extent, the initial confusion was alleviated by the iterative dynamics of the design-inquiry process:

The first iteration was a very important catastrophe, whereupon I changed a lot of what I thought as success until that moment. In the second and the third iteration more significant things have happened.... Iterations showed me how much there is more to do.... But I was satisfied, that does not mean that the time had been wasted - really not. Over this period I learned a lot about how these processes are conducted, I work in a structured and thorough manner, and experienced in many areas that were completely new to me.

A recurring theme in students' reflection is their difficulty in concretisation of theories and abstract ideas. This observation is in line with the findings of Fuhrmann and Kali (2010). Again, the fact that students reflect on this issue indicates that they are aware of it, and some of their comments suggest that the process helped them to take steps to address it: 
There is no doubt that an implementation of mobile learning is not so easy, there is a need to do a combination of many complicated factors, I thought I know exactly how I want that our activity will occur until this lesson. When we started to discuss as a group about the scenario I understood how much there is a lot of work to do. Suddenly very important issues came up and there were many things that we had to decide about.

The design-inquiry process at the centre of this course was supported by a variety of tools, methods and representations: a project site template, a design scenario template, force maps, design principles, storyboards, and so on. Indeed, students acknowledged the value of these tools:

- "Creating a story board focused us ... the story board enabled us to think deeper about our project, it focused our thoughts and showed us that we made some mistakes about things that we thought will work well."

- "We started to connect the design principles to our project, through the drawing and the ideas arrangement we reached to an amazing subject and into more deeply project that is more relevant to the research ... and the picture that we sketched helped us to discover and analyse every step in this progress."

- "The use of templates was very helpful especially with issues that I don't give them much attention, for example: How can I measure success of a project? How can I do preceding research etc."

Classroom sessions focused on guided group work and groups' presentation of their progress to the course assembly. Students commented on the contribution of these interactions to their learning:

When we saw the work of other teams I saw how different perspectives in the community can help us to add, delete, improve and modify various aspects of our project. Other points of view sometimes direct us in our actions and especially in the process of consolidation of the ideas behind them.

\section{Evaluating student's achievements}

All 29 students completed the courses successfully, and their feedback (at the end of course survey) suggests that they valued its contribution to their understanding of the core issues presented, as well as the pragmatic considerations of implementing these ideas in realistic educational contexts.

Students expressed notable criticism about the courses' administrative aspects, as well as the workload, which exceeded their expectations. Despite these shortcomings, the students all acknowledged the effectiveness of the design studio approach, some noting that it has changed their attitude to the course subjects and to technologyenhanced education in general.

Six projects were in the mobile learning course, completed and are now available as open resources (in Hebrew) at courses.edtech.haifa.ac.il/mlearning/projects. Nine projects were completed in the games and learning course and are available at courses.edtech.haifa.ac.il/games/projects

Upon completion, the projects were evaluated according to the rubric in Table 3.

Table 4 shows the results of this evaluation for the projects in the mobile learning course.

Table 5 shows the evaluation results for the games and learning course. 


\section{Y. Mor and O. Mogilevsky}

Table 3. Project evaluation rubric.

Theory and case Does the project review relevant theoretical works and case studies? Is the studies review critical and systematic? Do the outcomes inform the design?

Design and development Is the context adequately described? Is the problem well-defined? Is the proposed solution viable, robust, creative and fit for purpose?

Enactment Was the designed solution trailed in authentic conditions, as appropriate for the context and problem description and project constraints?

Were data from the design, development and enactment phases collected and Evaluation analysed systematically to assess the effectiveness of the solution, and reflect back on the theory, the design and its implementation?

Presentation Is the project presented in a clear, informative, and attractive manner?

Several students chose to continue their projects as a final project for their degree. At least one team is still developing their project and collecting data. One student reported that the core features of his project were incorporated into a large-scale initiative run by a national school network. These examples suggest that the courses had an impact which extended far beyond its presentation cycle - and one which affected participants' long-term professional practices.

In order to test this hypothesis, we surveyed the students again 2 years after the course completion. The web-based survey consisted of nine questions. Students were invited by email using the mailing lists created at the time of the course presentations. Sixteen students responded (seven from the mobile learning course, nine from the games and learning course). The results are shown in Figure 3.

These results indicate that students acknowledge the long-term effects of the courses, both in terms of enhancing their theoretical knowledge and in terms of improving their professional practice.

\section{Discussion}

Inquiry learning stems from the realisation that learning is more effective when grounded in active exploration of questions which are meaningful to the learners. This is also true for adults wishing to make use of technology in their teaching. In the model presented in this article, student projects were grounded in a context meaningful to them, thus making the course content personally relevant. Theories and case studies were not discussed in the abstract: they were scrutinised and used with regard to personally meaningful dilemmas. Inquiry learning proceeds through a

Table 4. Evaluation of projects in the mobile learning course.

\begin{tabular}{|c|c|c|c|c|c|c|}
\hline Id & Theory and case studies & $\begin{array}{c}\text { Design and } \\
\text { development }\end{array}$ & Enactment & Evaluation & Presentation & Total \\
\hline Weight & 10 & 10 & 10 & 10 & 10 & 50 \\
\hline 1 & 7 & 10 & 10 & 8 & 10 & 45 \\
\hline 2 & 7 & 10 & 10 & 8 & 7 & 42 \\
\hline 3 & 10 & 10 & 10 & 8 & 8 & 46 \\
\hline 4 & 7 & 10 & 10 & 10 & 10 & 47 \\
\hline 5 & 6 & 10 & 10 & 8 & 10 & 44 \\
\hline 6 & 7 & 9 & 5 & 9 & 9 & 39 \\
\hline Average & 7.71 & 9.86 & 9.29 & 8.71 & 9.14 & 44.71 \\
\hline
\end{tabular}


Table 5. Evaluation of projects in the games and learning course.

\begin{tabular}{lcccccc}
\hline Id & $\begin{array}{c}\text { Theory and } \\
\text { case studies }\end{array}$ & $\begin{array}{c}\text { Design and } \\
\text { development }\end{array}$ & & & & \\
Enactment & Evaluation & Presentation & Total \\
\hline $\begin{array}{l}\text { Weight } \\
\text { (gamification/ }\end{array}$ & & & & & & \\
application project) & 10 & 10 & 5 & 15 & 10 & 50 \\
\hline Weight (development & & & & & & \\
project) & 10 & 20 & 0 & 10 & 10 & 50 \\
\hline 1 & 10 & 10 & 5 & 10 & 8 & 43 \\
2 & 10 & 10 & 5 & 15 & 10 & 50 \\
3 & 8 & 16 & 5 & 12 & 10 & 51 \\
4 & 9 & 18 & 5 & 10 & 8 & 50 \\
5 & 7 & 20 & 5 & 10 & 9 & 51 \\
6 & 7 & 15 & 5 & 10 & 9 & 46 \\
7 & 5 & 10 & 5 & 15 & 10 & 45 \\
8 & 5 & 7 & 5 & 10 & 8 & 35 \\
9 & 10 & 10 & 5 & 15 & 6 & 46 \\
Average & 7.89 & 12.89 & 5.00 & 11.89 & 8.67 & 46.33 \\
\hline
\end{tabular}

cycle of asking questions, investigating those questions by conducting observations, collecting data, analysing and modelling it, and deriving conclusions, creating new understandings by synthesising the outcomes of the investigation, discussing these understandings with peers and teachers, and finally reflecting on the process and deriving new questions for the next cycle of inquiry (Anastopoulou et al. 2012;

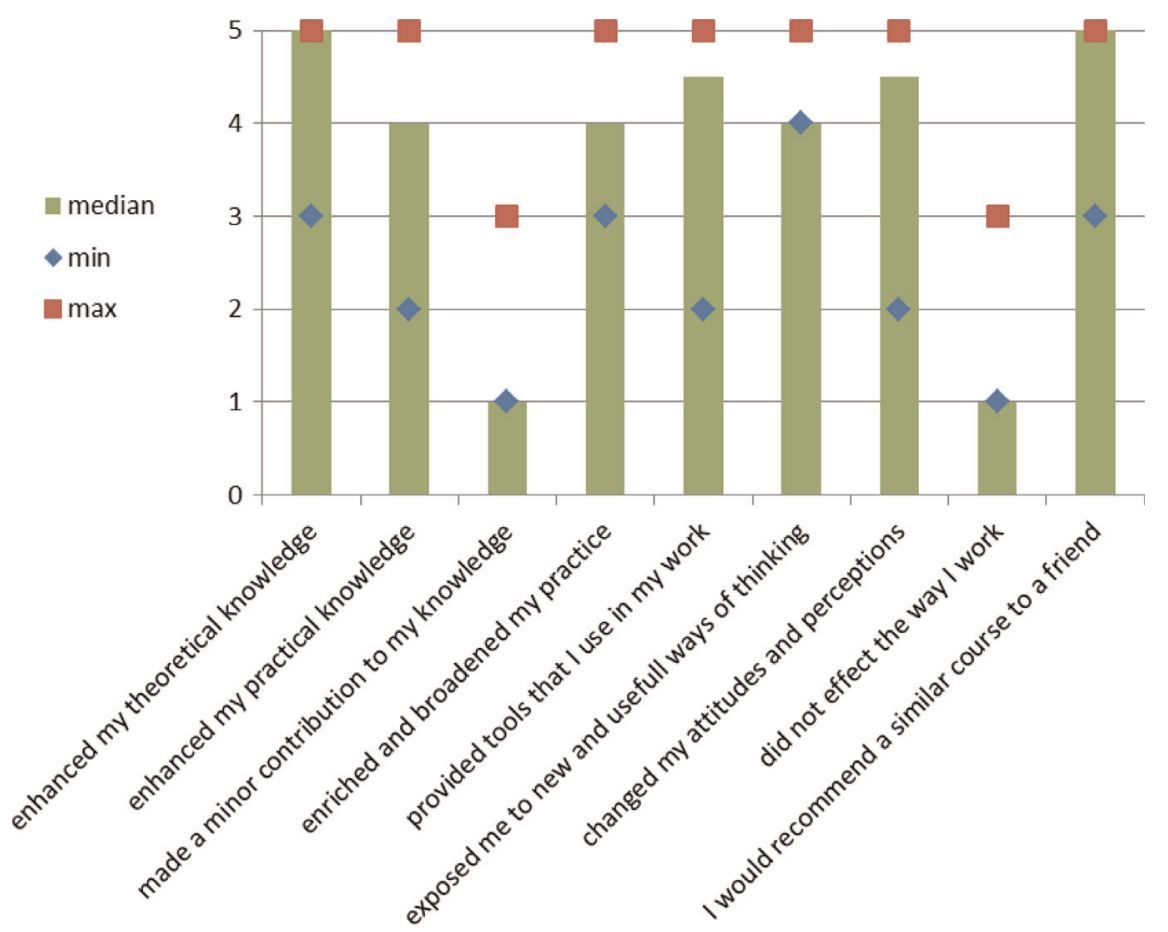

Figure 3. Results from the long-term effect survey. 
Kolodner et al. 2003). The LDS builds on this model and adapts it to a design research paradigm. Thus, students' investigation was conducted through the design and implementation of techno-pedagogical innovations.

A design-inquiry approach is driven by the pedagogical objectives and a pragmatist exploration of the potentials of technology to address those - rather than working from the tool to its possible uses. Students were asked to identify educational needs, define a pedagogical approach and then subject the choice of technologies to those. Although some reported that at first this requirement caused confusion and frustration, by the end of the course all acknowledged its value.

Kolodner et al. (2003) note LBD's roots in cognitive apprenticeship, case-based reasoning, and constructionism (among others), and emphasise the importance of the collaborative dimension in this mode of learning. The LDS adopts these features: the dynamic of the studio process naturally fosters an apprenticeship relationship between tutor and students. The "inspire" phase embeds cases into the learning trajectory and the challenges which emerge in the design process provide further cases - derived directly from learners' experience. The principles of constructionism are central to the learning experience: constructing knowledge by constructing and sharing meaningful artefact. Collaborative learning within and between groups played a significant part in students' learning process, engendering reflection and critical thinking. It enhanced their inquiry through feedback, support and workload distribution within groups. The feedbacks between groups and sharing the opinions in class discussions helped the students in constructing new meanings and juxtaposition different points of view. The dialogue established among the students and with the teacher and supported by the studio's approach is reflected by the students' reports as a useful method, which alleviated their difficulties in the course.

However, LBD, as Kolodner et al. (2003) note, is a problem-based approach. Green and Bonollo (2003, pp. 271) make an important distinction: in problem-based learning "a student is given a problem and then proceeds to solve [...] in projectbased learning, students may have to find or establish the problem." This distinction is critical for the LDS: identifying and formulating the educational challenge is one of the foundational steps of any educational innovation, and - as some students testified - a hard habit to learn (or teach). For this reason, it is an essential element of the LDS, perhaps what earns it the "design studio" name.

Educational work is always highly contextualised. The courses devoted significant attention to documenting and articulating the context in which the pedagogical challenge is situated, and carefully referring to that context in the design of the solution. As discussed by Mor (2011), this challenge of getting students to analyse context is far from resolved, but the courses showed promising signs in this respect.

In this article, we described "Biophone" as an exemplar project which was developed as part of the mobile learning course. The description of this project illustrates how the students applied the LDS methodology and developed a practical product. "Biophone" project constitutes the formulation of concept and its way through various milestones up to the transformation into existing invention. Doing such a successful project in a short semester course reinforces the fact that the teaching methods of the course and the tools given during it were successful.

Table 6 lists some of the main factors that contributed to the success of the LDS model. The selection and labels of these factors draw on design principles of problem and project-based learning (Barron et al. 1998) and LBD (Kolodner et al. 2003). 


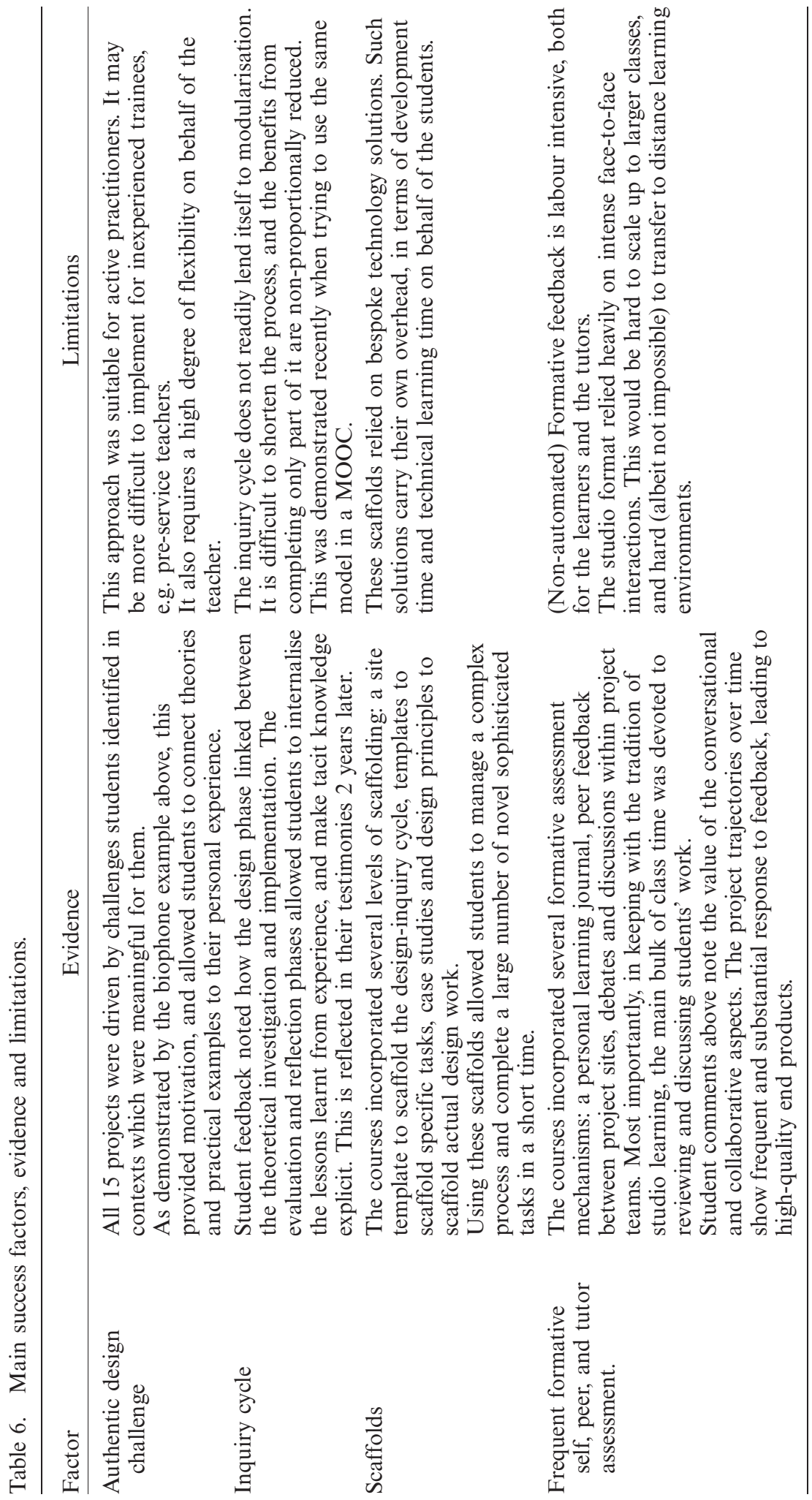




\section{Y. Mor and O. Mogilevsky}

Students consistently reported high workload and confusion. The main cause for this was the triple learning challenge: students were required to take on an unconventional pedagogy, using unfamiliar tools, to confront novel subject matter.

In order to scale up the LDS to a general framework for teacher education, the model and the supporting resources need to be refined, extended and evaluated at greater length. The model needs to be documented and explained in a comprehensive manner. Examples need to be provided for each phase and task. A unified, comprehensive, streamlined technological environment needs to be developed to support the process.

\section{Conclusions}

Looking back over several decades of research, technology-enhanced learning has established itself as a significant field of scientific inquiry. Yet projecting the outputs of research into practice remains a challenge. Teacher training needs to address this gap, and there are several reasons for adopting a design-inquiry approach, where students learn through developing techno-pedagogical innovations in their domain of practice.

Specifically, as demonstrated above, the LDS model appears to have the potential to achieve several aims, which are critical to the understanding and application of technology-enhanced learning:

- Acknowledging the importance of context, and developing tools for documenting and articulating context.

- Working from a pedagogical challenge grounded in a concrete educational context, rather than from a technological innovation stance in search of an application.

- Adapting rigorous habits of design inquiry modelled after the ideal of the design experiment - but adapted to the needs and constraints of educational practitioners.

- Combining personal construction and reflection with collaboration and communication as drivers of effective learning.

Educational practitioners often operate on the basis of their intuition and find it difficult to bind these to pedagogical theory. To counter this tendency, and to allow them to retain their tacit pragmatic knowledge while adopting an attitude of scientific rigor, they need to acknowledge their role as designers of learning experiences. The suggested model may serve as a framework for those who aim to train educators as clear and conscious decision makers. With well-defined guidelines and a supportive environment, teachers may become better learning designers. It allows educational professionals to connect scientific research to their practice and acquire the skills to identify educational challenges and devise effective means for addressing them.

\section{References}

Barron, B., et al. (1998) 'Doing with understanding: lessons from research on problem-and project-based learning', Journal of the Learning Sciences, vol. 7, no. 3-4, pp. 271-311.

Beetham, H. \& Sharpe, R. (2013) Rethinking Pedagogy for a Digital Age: Designing for 21st Century Learning, Routledge, Oxon. 
Cox, C., Harrison, S. \& Hoadley, C. (2008) "Applying the "studio model" to learning technology design', Educating learning technology designers: guiding and inspiring creators of innovative educational tools, eds C. DiGiano, S. Goldman \& M. Chorost, Routledge, NY, $145-164$.

Cross, S., et al. (2008) 'Mapping a landscape of learning design: Identifying key trends in current practice at the Open University', In: 2008 European LAMS Conference, 25-27 June 2008, Cadiz, Spain.

Fuhrmann, T. R. \& Kali, Y. (2010) 'The role of concretization in acquiring design knowledge', Learning in the Disciplines: Proceedings of the 9th International Conference of the Learning Sciences (ICLS 2010), eds K. Gomez, L. Lyons \& J. Radinsky, vol. 1, pp. 468-475. Full papers, International Society of the Learning Sciences, Chicago IL.

Fuhrmann, T. R., Kali, Y. \& Hoadley, C. (2008) 'Helping education students understand learning through designing', Educational Technology, vol. 48, pp. 26-33.

Green, L. N. \& Bonollo, E. (2003) 'Studio-based teaching: history and advantages in the teaching of design', World Transactions on Engineering and Technology Education, vol. 2, pp. 269-272.

Hattie, J. (2009) Visible learning: A synthesis of over 800 meta-analyses relating to achievement, Routledge, Oxon.

Hoadley, C. \& Cox, C. (2009) 'What is design knowledge and how do we teach it?', in Educating learning technology designers: guiding and inspiring creators of innovative educational tools, eds C. DiGiano, S. Goldman \& M. Chorost, Routledge, NY, pp. 19-35.

Josselson, R. \& Lieblich, A. (2001) 'Narrative research and humanism' in The Handbook of Humanistic Psychology, Sage, CA. pp. 275-288.

Kali, Y. (2006) 'Collaborative knowledge building using a design principles database', International Journal of Computer-Supported Collaborative Learning, vol. 1, pp. 187-201.

Kali, Y. \& Ronen-Fuhrmann, T. (2011) 'Teaching to design educational technologies', International Journal of Learning Technology, vol. 6, no. 1, pp. 4-23.

Kolodner, J. L., et al. (2003) 'Problem-based learning meets case-based reasoning in the middle-school science classroom: putting learning by design ${ }^{\mathrm{TM}}$ into practice', Journal of the Learning Sciences, vol. 12, no. 4, pp. 495-547.

Korthagen, F., et al. (2001) Linking Practice and Theory: The Pedagogy of Realistic Teacher Education, Lawrence Erlbaum, Mahwah, NJ.

Laurillard, D. (2008) 'The teacher as action researcher: using technology to capture pedagogic form', Studies in Higher Education, vol. 33, pp. 139-154.

Laurillard, D. (2012) Teaching as a Design Science: Building Pedagogical Patterns for Learning and Technology, Routledge, Florence, KY.

Mor, Y. (2010) 'A design approach to research in technology enhanced mathematics education', $\mathrm{PhD}$ thesis, Institute of Education - University of London.

Mor, Y. (2011) 'Context is what we take for granted: addressing context in designcentric teacher training', Context and Technology Enhanced Learning (ConTEL): Theory, Methodology and Design Workshop, at EC-TEL 2011, 21/9/2011, Palermo.

Mor, Y. \& Craft, B. (2012) 'Learning design: reflections on a snapshot of the current landscape', Research in Learning Technology, vol. 20. DOI: 10.3402/rlt.v20i0.19196

Mor, Y. \& Mogilevsky, O. (2012) 'A learning design studio in mobile learning', The 11th World Conference on Mobile and Contextual Learning (mLearn 2012), 16-18 October, Helsinki.

Mor, Y., Warburton, S. \& Winters, N. (2012) 'Participatory pattern workshops: a methodology for open learning design inquiry', Research in Learning Technology, vol. 20. DOI: 10.3402/ rlt.v20i0.19197

Mor, Y. \& Winters, N. (2007) 'Design approaches in technology enhanced learning', Interactive Learning Environments, vol. 15, pp. 61-75.

Simon, H. A. (1996) The Sciences of the Artificial - 3rd Edition, The MIT Press, Cambridge, MA.

Voogt, J., et al. (2011) 'Teacher learning in collaborative curriculum design', Teaching and Teacher Education, vol. 27, no. 8, pp. 1235-1244. 